\title{
Quality of life assessment in total laryngectomized patients rehabilitated with voice prosthesis
}

\author{
Abstract \\ To correlate voice prosthesis devices (VP) with voice intelligibility and quality of life in \\ laryngectomized patients (QoLLP).
}

Methods: C30 and H\&N35 quality of life questionnaires European Organization for Research and Treatment of Cancer (EORTC) and Harrinson Robillard-Schultz Rating Scale for tracheoesophageal voice were used to evaluate 61 patients submitted to total laryngectomy or pharyngolaryngectomy and rehabilitated with primary or secondary voice prosthesis (VP).

Results: A moderate but statistically significant correlation between the regular use of VP and voice intelligibility was verified. No statistically significant differences for major rating/items of assessment questionnaires of Quality of Life (QoL) according to the use of VP neither for the existing patients who have placed primary/secondary VP.

Conclusion: Patients who present a more intelligible speech are the ones who usually use VP. QoL items constipation, taste and smell, speech, social contact and sexuality showed significantly better levels in those patients who used more frequently VP. Voice rehabilitation using VP considerably improves QoL and social reintegration of laryngectomized patients and so we consider this method as an effective option for the rehabilitation of our patients.

Keywords: quality of life, laryngectomies, voice prosthesis, vp, eortc, qol, tl, hrqol, tev, provox
Volume 6 Issue 5 - 2017

\author{
J Castro Silva,' Susana Reis, ${ }^{1,2}$ Rita Viana, ${ }^{2}$ \\ Eurico Monteiro2 \\ 'Escola Superior de Saúde da Universidade de Aveiro, Portugal \\ ${ }^{2}$ Instituto Português de Oncologia Francisco Gentil do Porto, \\ Portugal
}

Correspondence: J Castro Silva, Instituto Português de Oncologia Francisco Gentil do Porto (IPOPFG, EPE), Rua Dr António Bernardino de Almeida 4200-072 Porto, Portugal, Email j.castrosilva@hotmail.com

Received: November 05, 2016 | Published: April 12, 2017
Abbreviations: EORTC, european organization for research and treatment of cancer; VP, voice prosthesis; QOL, quality of life; $\mathrm{TL}$, total laryngectomy; TEO, tracheo esophageal voice

\section{Introduction}

Total laryngectomy (TL) is a traditional surgical procedure directed to patients with larynx and/or hypopharynx tumors in advanced stage, and is associated to deep anatomical and physiological modifications, that include loss of laryngeal voice, swallowing problems, loss of nasal function with changes in smell and taste, loss of cough reflex and several other changes in pulmonary functions. Moreover, this procedure has important psychological consequences for all patient's life. ${ }^{1}$ TL can be applied in the treatment of laryngeal tumors, or may be associated with radiotherapy or chemoradiotherapy treatments. These treatments options are usually associated with several secondary effects, with important physical and psychological impact, and consequent alterations in the well-being and socialization. ${ }^{2}$ Laryngectomies patients have profound changes in the verbal capacity that affects in a large scale their communication abilities. ${ }^{3}$

Vocal rehabilitation of these patients has been a vital subject over the last decades, tending the actual interest in QoL related questions. ${ }^{3}$ Nowadays, professionals who work in oncologic institutions try to give to the patients a similar quality of life they had before the disease, based in patterns of QoL evaluation. This tendency is also applied to laryngectomies patients. For these patients, factors such as phonation, swallowing, breathing and aesthetics are relevant questions.

QoL is a relatively new concept in oncology practice, however not a common concept in assessing head and neck oncologic treatment results in Portuguese patients. ${ }^{4}$ According to the World Health Organization, QoL is expressed by the individual perception of their position in life, in the context of cultural systems and values, in relation to their goals, expectations, standards and concerns. When applied to the health context, this concept is defined as "Health-Related Quality of Life (HRQoL)", translating the impact of the disease and treatments in patient's personal, professional and sociocultural domains. The QoL and HRQoL concepts are related but the latter is directly related to the disease and its treatment. ${ }^{5}$ There are several organizations addressing this theme and some of them responsible for the creation of QoL assessment scales in oncology. EORTC is one of these organizations focused to oncologic diseases trying to correlate patients' survival patterns with their QoL.

In order to attain the above mentioned objectives, this organization has developed several QoL assessment scales, such as QLQ-C30 (applied to all cancer types) and QLQ-H\&N35 (specific module for head and neck tumors). ${ }^{5}$

Over the years, several methods of vocal rehabilitation for laryngectomies have been developed, such as oesophageal voice, electrolarynx and, more recently, tracheoesophageal voice (TEV) (Jongmans et al. 2006). Overall methods, TEV is the one that shows better results in terms of voice quality, with low rate of complications, so that currently many oncological centers use this option for vocal rehabilitation opposed to oesophageal voice. ${ }^{1}$

TEV is the combination of three factors: expiratory air flux directed to the phonatory prosthesis, neoglottis and/or effects of the remaining structures vibration and physiologic aspects of the upper respiratory system.

Success rate of these devices is between $50 \%$ and $90 \%$ (Jongmans et al. 2006; Bussu et al. 2011). Insertion of VP may be done during the laryngectomy (primary) or in a second time (secondary), usually after the end of complementary treatment. ${ }^{1}$ After the placement of the VP, 
patients are generally referred to Speech Therapists, in order to achieve or improve their vocal quality, so that they can reach an acceptable and intelligible speech, achieving a way to make themselves be orally understood.

Voice generated by non-laryngeal structures is characterized by changes in the acoustic basis, which brings implications on perception. These changes reduce intelligibility patterns and are also a limitative aspect to psychosocial and communicative levels. Another factor which generally influences communication is the regularity of the VP use, associated with some factors such as the diameter and shape of tracheostomy hole, presence of respiratory problems and the ability to do an effective occlusion of the stoma. ${ }^{6}$

The results of VP use may be assessed through the Harrinson Robillard-Schultz Rating Scale for tracheoesophageal voice that divides this parameter in 5 items, from the non-use to the use of the $\mathrm{VP}$ as the elective communication mean.?

\section{Methodology}

The objective of the analysis is to collect information about QoL of total laryngectomies rehabilitated with VP, relating the results with the utilization regularity, voice intelligibility patterns and the timing of placement of the device. So all the patients selected were rehabilitated with VP and a control group wasn't needed.

This study include 61 total laryngectomy patients from the Otolaryngology Department of the Portuguese Institute of Oncology Francisco Gentil in Porto, Portugal (IPOPFG, EPE), rehabilitated in terms of voice and who frequent Speech Therapy and Otolaryngology periodic consultations. From these 61 patients, two were excluded, one that abandoned Speech Therapy regular follow-up and the other due to the deterioration of health conditions because of tumor relapse. All the participants were rehabilitated through the placement of a model Provox ${ }^{\circledR}$ VP.

This analysis includes patients submitted to total laryngectomy or pharyngolaryngectomy with an average time of use of the VP equal or superior to three months. Patients under 18 years of age were excluded (ethical reasons/0 patients), as well as those who had physical limitations with implications in participating in the study and those who were rehabilitated in other Institutions.

Sample characteristics are shown in Table 1.

Table I Sample characterization

\begin{tabular}{|c|c|c|c|}
\hline Qualitative Variables & n (\%) & Quantitative Variables & $\begin{array}{l}\text { Average } \pm \\
\text { Divert -Pattern }\end{array}$ \\
\hline Sex & & Age & $63.07 \pm 10.20$ \\
\hline Male & $53(89.83 \%)$ & $\begin{array}{l}\text { Time (months) afterVP placement until the } \\
\text { applying of measurement instruments }\end{array}$ & $29.98 \pm 31.43$ \\
\hline Female & $6(10.17 \%)$ & Number of sessions of Speech Therapy & $14.17 \pm 9.68$ \\
\hline \multicolumn{4}{|l|}{ Tumor Location } \\
\hline Larynx & $5 \mathrm{I}(86.44 \%)$ & & \\
\hline Hipopharynx & $6(10.17 \%)$ & & \\
\hline Oropharynx & $2(3.39 \%)$ & & \\
\hline \multicolumn{4}{|l|}{ Surgery Type } \\
\hline Total Laryngectomy & $46(77.97 \%)$ & & \\
\hline Total Pharyngolaryngectomy & $13(23.03 \%)$ & & \\
\hline \multicolumn{4}{|l|}{ Additional Treatment } \\
\hline Yes & 45 (76.27\%) & & \\
\hline No & $14(23.73 \%)$ & & \\
\hline \multicolumn{4}{|l|}{ VP Placement } \\
\hline Primary Puncture & 4 I (69.49\%) & & \\
\hline Secundary Puncture & $18(30.51 \%)$ & & \\
\hline \multicolumn{4}{|l|}{ Type of Occlusion of Tthe Tracheostomy } \\
\hline Digital Occlusion & $16(27.12 \%)$ & & \\
\hline Simple Fenestrated cannula Portex ${ }^{\circledR}$ & $3(5.08 \%)$ & & \\
\hline $\begin{array}{l}\text { Simple fenestrated cannula Provox } ® \text { with heat } \\
\text { and moisture exchanger (HME) }\end{array}$ & $35(59.32 \%)$ & & \\
\hline Adhesive with HME Provox ${ }^{\circledR}$ & $4(6.78 \%)$ & & \\
\hline Larybutton with HME Provox® & I (I.69\%) & & \\
\hline \multicolumn{4}{|l|}{ Tumor Relapse } \\
\hline Yes & $4(6.78 \%)$ & & \\
\hline No & 55 (93.22\%) & & \\
\hline
\end{tabular}

Assessment instruments used in this study were QLQ-C30 (version 3), QLQ-H\&N35 (version 4) and for items of intelligibility and use of the device the Harrinson Robillard-Schultz Rating Scale.

QLQ-C30 (version 3) incorporates five functional scales (physical, performance, cognition, emotional and social), three symptoms scales (fatigue, pain, nausea and vomits), the global status of QoL health and six simple items to assess symptoms and other problems (dyspnea, loss of appetite, insomnia, financial difficulties, constipations and diarrhoea)
QLQ-H\&N35 adds seven symptoms scales (pain, swallowing, taste and smell, speech, eating in public, social contact and sexuality) and 11 simple items.

Both QoL questionnaires used are translated into European Portuguese, and QLQ-C30 is certified for the same language. ${ }^{8}$

Harrinson Robillard-Schultz Rating Scale for tracheoesophageal prosthesis is defined for its success rate in three parameters: use (level in which TEV is used as first mean of communication), intelligibility 
(ease to produce TEV and its effects in speech intelligibility) and hygiene care (patient's autonomy and professional help in the maintenance of fistula and VP). This scale is translated into Portuguese, but not certificated. ${ }^{?}$

After approval by the Ethics Commission of IPOPFG, EPE, the project was implemented in the ORL Department. At first, patient's clinical processes were analysed, and the following information was collected: age, sex, tumor location, type of surgery, complementary treatments, VP placement opportunity, mean time of use of VP, number of speech therapy sessions and current health stage of the patients.

In order to apply QoL questionnaires and, to assess intelligibility and use of VP items and the method of tracheostomy occlusion, a Speech Therapy appointment was scheduled. An authorization was requested to all patients, through an informed consent about the extent, framework, objectives and relevance of the study.

QoL questionnaires were filled by the patients, without any supervision, and in a few cases they were sent by e-mail. In cases in which patients had eye and/or motor difficulties, or in cases they denied to answer alone, the researchers filled the questionnaires after the patient's answer to each question.

The rating scale and QoL questionnaires were scored according to the application manual of each instrument.

The analysis software used for analysis was SPSS version 20.0. Spearman correlation was calculated to correlate the variables of use and the intelligibility of VP. Anova was applied in a number of independent samples, as well as the Kruskal-Wallis test, depending on whether the assumptions were accomplished or not, with the objective of verifying whether the level of QoL was different on the basis of VP utilization. Some items and ratings were under multiple comparisons. $\mathrm{U}$ Mann-Witney test were used to collect information between the placement of VP and QoL. In all statistic procedures a significance level of 0.05 was used.

\section{Results}

Table 2 depicts the results of the correlation between the use of TEV (U1: never uses the TEV; U2: uses TEV less than $50 \%$ of the time; U3: Uses TEV between $50 \%$ and $80 \%$ of communication opportunities: U4: uses TEV as the main communication mean) and voice intelligibility (I1: incapable of producing sound; I2: voice too tense or too blowing, being impossible to use in conversation; I3: the stoma is often poorly occluded resulting in a air leakage, which interferes with the intelligibility of speech; I4: the voice is mildly tense or gently blown, but it is possible to use in conversation, the stoma occlusion is generally good, and the speech is intelligible; I5: voice is easily produced, with good stoma occlusion and intelligible voice).

Table 2 Use and Intelligibility of TEV

\begin{tabular}{lccccc}
\hline Intelligibility & U1 & U2 & U3 & U4 & Total \\
\hline Use of TEV & & & & & \\
\hline II & 5 & 0 & 0 & 0 & 5 \\
12 & 0 & I & 0 & 0 & 1 \\
13 & 2 & 1 & 1 & 0 & 4 \\
14 & 2 & 4 & 3 & 7 & 16 \\
I5 & 0 & 2 & 5 & 26 & 33 \\
Total & 9 & 8 & 9 & 33 & \\
\hline
\end{tabular}

The Spearman coefficient was statistically significant $(\mathrm{p}=0.000)$, i. e., the level of TEF intelligibility rises with the use of VP. Most part of the patients who produce voice easily uses VP as elective mean of communication.

Spearman correlation value is moderate and positive, $\mathrm{r}(59)=$ $0.677, \mathrm{p}<0.05$, which means a high dependency level between the variables.

Tables 3-6 present the results of the comparison between the level of QoL and the use of TEV. It was reported that the QoL level is similar for major scales/items of questionnaires QLQ C30 and QLQ H\&N35, independently of the use of VP. Nevertheless, it was also observed that for items: Constipation $(\mathrm{p}=0.028)$, Taste and Smell $(\mathrm{p}=0.012)$, Speech $(\mathrm{p}=0.000)$, Social contact $(\mathrm{p}=0.007)$, and Sexuality $(\mathrm{p}=0.034)$ patients who use VP have a higher level of QoL, comparing to those who use the device less often.

Table 3 EORTC-QLQ C30 questionnaire on the basis of the use of TEV

\begin{tabular}{|c|c|c|c|c|c|c|c|c|}
\hline \multicolumn{2}{|c|}{ EORTC-QLQ C30/Use of TEV } & \multicolumn{3}{|l|}{$U I(n=9)$} & \multicolumn{3}{|l|}{ U2 $(n=8)$} & \multirow[t]{2}{*}{$\mathbf{p}$} \\
\hline & & $A \pm D P$ & Aver. & AIQ & $A \pm D P$ & Aver. & AIQ & \\
\hline \multirow[t]{5}{*}{ Functional Rating } & Physical & $64.6 \pm 20.9$ & 67 & 37 & $76.5 \pm 23.8$ & 80 & 40 & 0.068 \\
\hline & Performance & $83.3 \pm 27.5$ & 100 & 25 & $81.3 \pm 24.3$ & 91.5 & 33 & 0.512 \\
\hline & Social & $70.3 \pm 26.1$ & 67 & 50 & $95.8 \pm 7.9$ & 100 & 13 & 0.063 \\
\hline & Emotional & $75.0 \pm 23.0$ & 75 & 38 & $80.3 \pm 19.5$ & 87.5 & 38 & 0.809 \\
\hline & Cognitive & $79.6 \pm 24.7$ & 83 & 42 & $95.8 \pm 7.9$ & 100 & 13 & 0.499 \\
\hline \multirow[t]{4}{*}{ Symptoms Rating } & Fatigue & $35.3 \pm 29.2$ & 42 & 33 & $15.1 \pm 16.6$ & 11 & 28 & 0.104 \\
\hline & Pain & $35.1 \pm 34.7$ & 33 & 75 & $22.9 \pm 36.7$ & 0 & 46 & 0.167 \\
\hline & Nausea and Vomit & $5.6 \pm 11.7$ & 0 & 9 & $12.5 \pm 35.4$ & 0 & 0 & 0.985 \\
\hline & GlobalStatus of health & $54.6 \pm 22.5$ & 58 & 21 & $66.8 \pm 33.3$ & 75 & 56 & 0.111 \\
\hline \multirow[t]{6}{*}{ Simple items } & Dyspnea & $18.3 \pm 17.4$ & 33 & 33 & $8.3 \pm 15.3$ & 0 & 25 & 0.137 \\
\hline & Loss of appetite & $14.8 \pm 24.2$ & 0 & 33 & $12.5 \pm 35.4$ & 0 & 0 & 0.546 \\
\hline & Insomnia & $22.2 \pm 37.3$ & 0 & 50 & $20.9 \pm 39.7$ & 0 & 50 & 0.963 \\
\hline & Financial Difficulties & $22.1 \pm 23.6$ & 33 & 33 & $8.4 \pm 23.7$ & 0 & 0 & 0.409 \\
\hline & Constipation & $33.3 \pm 44.1$ & 0 & 84 & $25.0 \pm 38.9$ & 0 & 59 & 0.028 \\
\hline & Diarrhoea & $7.4 \pm 22.3$ & 0 & 0 & $4.1 \pm 11.7$ & 0 & 0 & 0.823 \\
\hline
\end{tabular}


Table 4 EORTC-QLQ C30 questionnaire on the basis of the use of TEV

\begin{tabular}{|c|c|c|c|c|c|c|c|c|}
\hline \multicolumn{2}{|c|}{ EORTC-QLQ C30/Use of TEV } & \multicolumn{3}{|l|}{ U3 $(n=9)$} & \multicolumn{3}{|l|}{ U4 (n=33) } & \multirow[t]{2}{*}{$\mathbf{p}$} \\
\hline & & A $\pm D P$ & Aver. & AIQ & A $\pm D P$ & Aver. & AIQ & \\
\hline \multirow[t]{5}{*}{ Functional Rating } & Physical performance & $81.6 \pm \mid 4.1$ & 87 & 17 & $81.8 \pm 15.0$ & 87 & 17 & 0.068 \\
\hline & Social & $87.0 \pm 27.3$ & 100 & 17 & $90.4 \pm 19.6$ & 100 & 9 & 0.512 \\
\hline & Emotional & $88.9 \pm 33.3$ & 100 & 0 & $85.8 \pm 20.5$ & 100 & 17 & 0.063 \\
\hline & Cognitive & $82.3 \pm 13.6$ & 83 & 21 & $82.4 \pm 21.4$ & 92 & 29 & 0.809 \\
\hline & Social & $88.9 \pm 14.3$ & 100 & 25 & $83.8 \pm 31.3$ & 100 & 17 & 0.499 \\
\hline \multirow[t]{4}{*}{ Symptoms Rating } & Fatigue & $15.9 \pm 16.6$ & 22 & 28 & $15.4 \pm 2 \mid .5$ & $\mathrm{II}$ & 22 & 0.104 \\
\hline & Pain & $16.1 \pm 23.6$ & 0 & 33 & $\mid \mathrm{I} . \mathrm{I} \pm 20.2$ & 0 & 17 & 0.167 \\
\hline & Nausea and Vomit & $5.6 \pm 11.7$ & 0 & 9 & $3.1 \pm 6.7$ & 0 & 0 & 0.985 \\
\hline & Global Status of health & $74.1 \pm 18.3$ & 75 & 33 & $75.8 \pm 17.4$ & 75 & 21 & 0.111 \\
\hline \multirow[t]{6}{*}{ Simple items } & Dyspnea & $14.7 \pm 17.4$ & 0 & 33 & $7.0 \pm 16.1$ & 0 & 0 & 0.137 \\
\hline & Loss of appetite & $18.4 \pm 24.2$ & 0 & 33 & $12.1 \pm 27.4$ & 0 & 0 & 0.546 \\
\hline & Insomnia & $14.8 \pm 24.2$ & 0 & 33 & $|8.1 \pm 25|$. & 0 & 33 & 0.963 \\
\hline & Financial Difficulties & $25.8 \pm 32.4$ & 33 & 33 & $20.2 \pm 31.2$ & 0 & 33 & 0.409 \\
\hline & Constipation & $33.3 \pm 37.3$ & 33 & 67 & $6.0 \pm 15.5$ & 0 & 0 & 0.028 \\
\hline & Diarrhoea & N.A. & N.A. & N.A. & $2.0 \pm 8.0$ & 0 & 0 & 0.823 \\
\hline
\end{tabular}

N.A. $=$ Not available in data, once the sample in these groups was zero

Table 5 EORTC-QLQ H\&N35 questionnaire on the basis of the use of TEV

\begin{tabular}{|c|c|c|c|c|c|c|c|c|}
\hline \multicolumn{2}{|c|}{ EORTC-H\&N35/ Use of TEV } & \multicolumn{3}{|l|}{$U I(n=9)$} & \multicolumn{3}{|l|}{ U2 (n=8) } & \multirow[t]{2}{*}{$\mathbf{p}$} \\
\hline & & $A \pm D P$ & Aver. & AIQ & A土DP & Aver. & AIQ & \\
\hline \multirow[t]{7}{*}{ Symptoms Rating } & Pain & $29.7 \pm 36.1$ & 17 & 59 & $10.5 \pm 14.8$ & 4 & 17 & 0.385 \\
\hline & Swallowing & $43.4 \pm 33.3$ & 33 & 55 & $21.9 \pm 33.3$ & 4 & 61 & 0.111 \\
\hline & Taste and Smell & $74.1 \pm 33.4$ & 100 & 59 & $60.4 \pm 23.6$ & 58.5 & 42 & 0.012 \\
\hline & Speech & $53.2 \pm 13.7$ & 56 & 29 & $43.0 \pm 24.3$ & 44 & 42 & 0 \\
\hline & Eating in public & 35.2 & 25 & 51 & $13.6 \pm 10.0$ & 17 & 21 & 0.079 \\
\hline & Social contact & $31.0 \pm 29.7$ & 33 & 44 & $15.1 \pm 15.5$ & 13.5 & 27 & 0.007 \\
\hline & Sexuality & $51.8 \pm 38.6$ & 50 & 75 & $52.0 \pm 44.0$ & 58 & 92 & 0.034 \\
\hline \multirow[t]{11}{*}{ Simple items } & Teeth problems & $40.8 \pm 43.5$ & 33 & 84 & $8.3 \pm 15.3$ & 0 & 25 & 0.257 \\
\hline & Trismus & $22.1 \pm 23.6$ & 33 & 33 & $8.3 \pm 15.3$ & 0 & 25 & I \\
\hline & Xerostomia & $25.9 \pm 27.9$ & 33 & 50 & $16.5 \pm 17.6$ & 16.5 & 33 & 0.784 \\
\hline & Thick saliva & $33.3 \pm 37.3$ & 33 & 67 & $16.6 \pm 35.6$ & 0 & 25 & 0.38 \\
\hline & Cough & $29.7 \pm 39.0$ & 0 & 67 & $41.6 \pm 34.6$ & 33 & 59 & 0.576 \\
\hline & Discomfort & $26.0 \pm 32.5$ & 0 & 67 & $12.5 \pm 24.9$ & 0 & 25 & 0.119 \\
\hline & Analgesic consumption & $22.2 \pm 44.1$ & 0 & 50 & $25.0 \pm 46.3$ & 0 & 75 & 0.479 \\
\hline & Food supplement & $33.3 \pm 50.0$ & 0 & 100 & $12.5 \pm 35.4$ & 0 & 0 & 0.091 \\
\hline & Feeding tube & $22.2 \pm 44.1$ & 0 & 50 & N.A. & N.A. & N.A. & 0.162 \\
\hline & Weight loss & $44.4 \pm 52.7$ & 0 & 100 & $25.0 \pm 46.3$ & 0 & 75 & 0.192 \\
\hline & Weight gain & $22.2 \pm 44.1$ & 0 & 50 & $50.0 \pm 53.5$ & 50 & 100 & 0.5 \\
\hline
\end{tabular}

Table 6 EORTC-QLQ H\&N35 questionnaire on the basis of the use of TEV

\begin{tabular}{|c|c|c|c|c|c|c|c|c|}
\hline \multicolumn{2}{|c|}{ EORTC-H\&N35/ Use ofTEV } & \multicolumn{3}{|l|}{ U3 $(n=9)$} & \multicolumn{3}{|c|}{ U4 (n=33) } & \multirow[t]{2}{*}{$\mathbf{p}$} \\
\hline & & $A \pm D P$ & Aver. & AIQ & $A \pm D P$ & Aver. & AIQ & \\
\hline \multirow[t]{7}{*}{ Symptoms Rating } & Pain & $7.3 \pm 13.5$ & 0 & 8 & $6.8 \pm 10.6$ & 0 & 13 & 0.385 \\
\hline & Swallowing & $15.8 \pm \mid 7.1$ & 8 & 34 & $16.9 \pm 19.6$ & 8 & 25 & 0.111 \\
\hline & Taste and Smell & $51.8 \pm 29.4$ & 50 & 42 & $35.9 \pm 28.0$ & 33 & 50 & 0.012 \\
\hline & Speech & $29.4 \pm 21.5$ & 33 & 33 & $16.8 \pm 18.9$ & II & 22 & 0 \\
\hline & Eating in public & $17.7 \pm 16.0$ & 17 & 30 & $12.1 \pm 16.6$ & 8 & 17 & 0.079 \\
\hline & Social contact & $14.1 \pm 12.2$ & 13 & 24 & $7.9 \pm 13.1$ & 0 & 7 & 0.007 \\
\hline & Sexuality & $42.7 \pm 40.9$ & 50 & 84 & $19.7 \pm 25.8$ & 0 & 33 & 0.034 \\
\hline \multirow[t]{11}{*}{ Simple items } & Teeth problems & $\mid I . I \pm 23.6$ & 0 & 17 & $18.2 \pm 32.4$ & 0 & 33 & 0.257 \\
\hline & Trismus & $7.3 \pm 14.6$ & 0 & 17 & $7.1 \pm 18.2$ & 0 & 0 & I \\
\hline & Xerostomia & $25.8 \pm 32.4$ & 33 & 33 & $17.1 \pm 22.2$ & 0 & 33 & 0.784 \\
\hline & Thick saliva & $18.4 \pm 33.8$ & 0 & 33 & $23.1 \pm 21.2$ & 33 & 33 & 0.38 \\
\hline & Cough & $22.2 \pm 29.0$ & 0 & 50 & $25.2 \pm 30.1$ & 33 & 33 & 0.576 \\
\hline & Discomfort & $3.7 \pm 11.0$ & 0 & 0 & $5.0 \pm 12.0$ & 0 & 0 & 0.119 \\
\hline & Analgesic consumption & $44.4 \pm 52.7$ & 0 & 100 & $18.2 \pm 39.2$ & 0 & 0 & 0.479 \\
\hline & Food supplement & N.A. & N.A. & N.A. & $6.1 \pm 24.2$ & 0 & 0 & 0.091 \\
\hline & Feeding tube & N.A. & N.A. & N.A. & $3.0 \pm 17.4$ & 0 & 0 & 0.162 \\
\hline & Weight loss & $22.2 \pm 44.1$ & 0 & 50 & $12.1 \pm 33.1$ & 0 & 0 & 0.192 \\
\hline & Weight gain & $33.3 \pm 50.0$ & 0 & 100 & $24.2 \pm 43.5$ & 0 & 50 & 0.5 \\
\hline
\end{tabular}

Citation: Silva JC, Reis S, Viana R, et al. Quality of life assessment in total laryngectomized patients rehabilitated with voice prosthesis. J Otolaryngol ENT Res. 20I7;6(5): I 58-I64. DOI: I0.I5406/joentr.2017.06.00I78 
Tables $7 \& 8$ show the results of the comparison of QoL levels between the patients who placed primary/ secondary VP. The results of the Mann-Witney and U test show there are no statistical significant differences between both groups.

Table 7 EORTC-QLQ questionnaire on the basis of VP placement

\begin{tabular}{|c|c|c|c|c|c|c|c|c|}
\hline \multicolumn{2}{|c|}{ EORTC-QLQ C30/Time of Surgery } & \multicolumn{2}{|l|}{ A $\pm D P$} & \multicolumn{2}{|l|}{ Aver. } & \multirow{2}{*}{$\begin{array}{l}\text { AIQ } \\
\begin{array}{l}\text { Ist Surgery } \\
n=4 \text { I }\end{array}\end{array}$} & \multirow{2}{*}{\multicolumn{2}{|c|}{\begin{tabular}{l}
\multicolumn{1}{c}{$p$} \\
2nd Surgery \\
$n=18$
\end{tabular}}} \\
\hline & & $\begin{array}{l}\text { I st Surgery } \\
n=4 \mid\end{array}$ & $\begin{array}{l}\text { 2nd Surgery } \\
n=18\end{array}$ & $\begin{array}{l}\text { Ist Surgery } \\
n=4 \mid\end{array}$ & $\begin{array}{l}\text { 2nd Surgery } \\
n=18\end{array}$ & & & \\
\hline \multirow[t]{4}{*}{ Functional Rating } & Physical & $77.1 \pm 18.8$ & $81.4 \pm 15.6$ & 80 & 83.5 & 23 & 26 & 0.455 \\
\hline & Social & $85.7 \pm 21.0$ & $84.2 \pm 28.3$ & 100 & 100 & 17 & 25 & 0.737 \\
\hline & Emotional & $82.1 \pm 20.8$ & $78.3 \pm 18.8$ & 83 & 79 & 25 & 29 & 0.327 \\
\hline & Cognitive & $83.3 \pm 26.9$ & $90.7 \pm 24.4$ & 100 & 100 & 25 & 4 & 0.167 \\
\hline \multirow{3}{*}{ Symptoms Rating } & Pain & $20.2 \pm 29.4$ & $10.3 \pm 17.4$ & 0 & 0 & 33 & 17 & 0.448 \\
\hline & Nausea and vomit & $6.5 \pm 17.4$ & $1.9 \pm 5.5$ & 0 & 0 & 0 & 0 & 0.365 \\
\hline & GlobalStatus of health & $67.9 \pm 22.6$ & $78.2 \pm 18.5$ & 67 & 83.0 .00 & 33 & 35 & 0.112 \\
\hline \multirow[t]{5}{*}{ Simple items } & Dyspnea & $12.9 \pm 18.0$ & $3.7 \pm 10.7$ & 0 & 0 & 33 & 0 & 0.059 \\
\hline & Loss of appetite & $13.0 \pm 26.7$ & $14.8 \pm 28.5$ & 0 & 0 & 17 & 33 & 0.855 \\
\hline & Insomnia & $19.4 \pm 29.8$ & $16.7 \pm 26.2$ & 0 & 0 & 33 & 33 & 0.765 \\
\hline & Financial Difficulties & $19.5 \pm 28.9$ & $20.3 \pm 30.6$ & 0 & 0 & 33 & 33 & 0.98 \\
\hline & Constipation & $20.3 \pm 32.4$ & $9.2 \pm 25.0$ & 0 & 0 & 33 & 0 & 0.175 \\
\hline
\end{tabular}

Table 8 EORTC-QLQ H\&N35 questionnaire on the basis of surgical type variable

\begin{tabular}{|c|c|c|c|c|c|c|c|c|}
\hline \multicolumn{2}{|c|}{ EORTC-H\&N35/Type of surgery } & \multirow{2}{*}{ 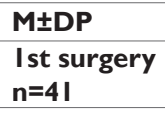 } & \multirow[b]{2}{*}{$\begin{array}{l}\text { 2nd surgery } \\
n=18\end{array}$} & \multirow{2}{*}{$\begin{array}{l}\text { Aver. } \\
\text { Ist surgery } \\
n=4 \text { I }\end{array}$} & \multirow[b]{2}{*}{$\begin{array}{l}\text { 2nd surgery } \\
n=18\end{array}$} & \multirow{2}{*}{$\begin{array}{l}\text { AIQ } \\
\text { Ist surgery } \\
n=4 \text { I }\end{array}$} & \multirow{2}{*}{\multicolumn{2}{|c|}{$\begin{array}{l}\quad \text { p } \\
\begin{array}{l}\text { 2nd surgery } \\
n=18\end{array}\end{array}$}} \\
\hline & & & & & & & & \\
\hline \multirow{7}{*}{$\begin{array}{l}\text { Symptoms } \\
\text { Rating }\end{array}$} & Pain & $10.8 \pm 16.9$ & $I I . I \pm 23.6$ & 0 & 0 & 17 & 17 & 0.894 \\
\hline & Swallowing & $24.0 \pm 27.0$ & $15.7 \pm 19.8$ & 17 & 8 & 38 & 25 & 0.334 \\
\hline & Taste and Smell & $50.8 \pm 30.3$ & $39.8 \pm 33.4$ & 0 & 33 & 34 & 54 & 0.219 \\
\hline & Speech & $31.4 \pm 22.6$ & $19.7 \pm 24.6$ & 33 & II & 39 & 44 & 0.054 \\
\hline & Eating in public & $16.9 \pm 18.0$ & $16.2 \pm 25.5$ & 17 & 8 & 25 & 19 & 0.442 \\
\hline & Social contact & $14.8 \pm 19.1$ & $10.1 \pm 16.0$ & 7 & 0 & 27 & 14 & 0.327 \\
\hline & Sexuality & $33.7 \pm 36.6$ & $29.7 \pm 33.6$ & 33 & 17 & 67 & 50 & 0.842 \\
\hline \multirow[t]{11}{*}{ Simple items } & Teeth problems & $19.5 \pm 29.8$ & $18.5 \pm 38.3$ & 0 & 0 & 33 & 8 & 0.465 \\
\hline & Trismus & $9.7 \pm 18.6$ & $9.2 \pm 19.1$ & 0 & 0 & 17 & 8 & 0.957 \\
\hline & Xerostomia & $20.2 \pm 24.6$ & $18.4 \pm 23.5$ & 0 & 0 & 33 & 33 & 0.875 \\
\hline & Thick saliva & $21.9 \pm 28.5$ & $25.8 \pm 26.9$ & 0 & 33 & 33 & 33 & 0.461 \\
\hline & Cough & $30.9 \pm 32.0$ & $20.3 \pm 30.6$ & 33 & 0 & 67 & 33 & 0.203 \\
\hline & Discomfort & $11.3 \pm 20.6$ & $3.7 \pm 15.8$ & 0 & 0 & 33 & 0 & 0.104 \\
\hline & $\begin{array}{l}\text { Analgesic } \\
\text { consumption }\end{array}$ & $22.0 \pm 41.9$ & $27.8 \pm 46.1$ & 0 & 0 & 0 & 100 & 0.742 \\
\hline & Food supplement & $12.2 \pm 33.1$ & $5.6 \pm 23.6$ & 0 & 0 & 0 & 0 & 0.656 \\
\hline & Feeding tube & $4.9 \pm 21.8$ & $5.6 \pm 23.6$ & 0 & 0 & 0 & 0 & I \\
\hline & Weight loss & $19.5 \pm 40.1$ & $22.2 \pm 42.8$ & 0 & 0 & 0 & 25 & $\mathrm{I}$ \\
\hline & Weight gain & $24.4 \pm 43.5$ & $38.9 \pm 50.2$ & 0 & 0 & 50 & 100 & 0.35 \\
\hline
\end{tabular}

\section{Discussion}

The concept of QoL comprises diverse fundamental domains in physical, psychological and social domains. Head and neck cancer patients are vulnerable to many psychosocial problems, once social interactions and emotional expressions depend mainly on structural and functional integrity of important areas. The impact of the diagnoses of head and neck cancer, as well as treatment consequences, has relevant influence in their lives, affecting their well-being and the QoL.

TL is an adequate treatment option for patients with malignant tumours of larynx and hypopharynx in advanced stages. However, the resulting functional limitations (physical, psychological, social and emotional alterations) influence patient's perception about his/ her own QoL. The way each patient deals with the diagnoses of a malignant tumour, the surgical procedure and its consequences depends on factors such as age, sex, economic condition, familiar support, psychological strategies, as well as the time elapsed after the surgery. ${ }^{9}$ Collected data from our patients show that those who use TEV as first mean of communication have a more intelligible speech. Speech Therapy after TL has the objective to help vocal rehabilitation of patients, improving their phonatory performance and speech intelligibility, providing fluency and intelligibility to the voice, contributing to the improve the communication and QoL. ${ }^{3}$

From the three voice rehabilitation methods, TEV is the most similar to laryngeal voice in its acoustic and perceptive characteristics. So, using VP in all communicative contexts, laryngectomies patients will improve their verbal ability and improve speech intelligibility.

Results obtained between the level of TEV use and QoL reveal that, for the major part of the applied questionnaires, QoL was not influenced by the use of VP. 
The inability of oral expression, the presence of a permanent tracheostomy and the fear of a tumor relapse are the most devastating consequences of TL, and all these contribute in a significant way to the inadequate perception of QoL by these patients. People's life suffers a drastic change. Breathing becomes affected by the tracheostomy, raising the risk of pulmonary infections, besides inhering in social interaction patterns. Taste and smell also suffer many changes, once the lack of larynx limits the airway through upper areas, influencing these senses. In terms of social contact and interaction, patients experiment communicative difficulties, both with people they known or with strangers. Thus, the loss of laryngeal voice causes invariably many disadvantages in psychological, social and economic levels.

It has been found that some patients who have good speech intelligibility refer not to use VP with regularity, aspect that we would not expect and consequently will induce a decrease in the perception of QoL. According to the patients and our evaluation, the less use of TEV as first mean of communication is due to the difficulty of occlusion of the tracheostomy owing to its shape (eg.: large, deep or irregular tracheostomy), the presence of chronic obstructive pulmonary pathology, side effects of complementary treatments as radiotherapy or chemoradiotherapy, financial problems that enable the acquisition of support systems, and absence of communication interest as a result of social isolation, aspects that are in agreement with the literature.

Nevertheless, it was verified that for the items: constipation, taste and smell, sexuality, speech and social contact, patients who use TEV as preferential means of communication have higher QoL level. These differences in appreciation of QoL, notwithstanding the small relevance of this study, may be based on several factors. With regard to the communication ability, the fact that patients who use usually TEV find it easier to communicate. ${ }^{10}$ Considering the social contact aspects, differences may occur because patients who use TEV more often, do not isolate themselves, and so don't allow that the presence of a TL and consequent voice deprivation as a limitative factor. Regarding the taste and smell, while training for acquisition of TEV, patients suffered vocal resonant cavities activation, causing a predictable impact in olfactory rehabilitation. This fact may explain the differences observed. About constipation, differences are not clinically explained by the results obtained. Finally, differences verified on the sexuality item, may be explained by the lack of interest and sexual pleasure conditioned by oncologic treatments and by the disease itself, but we can predict some greater interest due to the best communication skills of patients. ${ }^{10}$

Actually, it was not found in literature any study analysing the relation between TEV and QoL. However, many studies show that VP is an invaluable help for these patients, insofar as it promotes their selfconfidence and social interaction. Furthermore, laryngectomies feel much more satisfied with TEV, and all are unanimous in considering that VP has improved their QoL. In this context, vocal rehabilitation has many positive effects at the emotional level, as well as in social interaction, being a benefit aspect in their QoL. ${ }^{10}$

Regarding to the results of QoL in patients who have placed primary versus secondary VP, no significant differences were identified between both groups.

Over the last years, surgery for tracheoesophageal punction with the insertion of VP is considered an effective intervention with low complication rates. TEV is characterized by adequate voice intensity, better speech intelligibility and an increase in the level of patient's satisfaction in comparison to other methods of vocal rehabilitation.
Analyzing other published studies, VP placement in first or second option has achieved high success rates on vocal rehabilitation (65$85 \%$ e $69-83 \%$, respectively). ${ }^{7}$

The results obtained in this study, confirm what was mentioned above, significant differences between patients who have placed primary VP compared with those who have placed the device in a second surgical time ${ }^{7}$. Some authors highlight a high success rate tendency when the VP is primary placed. According to our results, either primary or secondary tracheoesophageal punction with Provox ${ }^{\circledR}$ VP are safe and efficient procedures, providing in patients similar satisfaction levels.

Possible reasons for this fact, may be due to our careful patients selection criteria, namely for secondary prosthesis placement, which are supported on the results of the insufflation test, sometimes in fluoroscopy and, in patient's determination and motivation to acquire voice. ${ }^{11-16}$

\section{Conclusion}

Laryngectomized patients who use VP to speak normally are the ones who show more intelligibility in verbal communication and better QoL indicators.

QoL items constipation, taste and smell, speech, social contact and sexuality showed significantly better levels in those patients who used more frequently VP. These indicators apparently are not influenced by the timing of placement of VP. Voice rehabilitation using VP considerably improves QoL and social reintegration of laryngectomized patients.

Our study shows improved quality of life in laryngectomized patients rehabilitated with VP, particularly those patients who actively use it. We consider this method as an effective option for the rehabilitation of our patients. The treatment of these patients should include multidisciplinary teams in the care of rehabilitation, including otolaryngologists, speech therapists and nurses. Particular attention should be given to clinical protocols that can encourage the use of VP by these patients.

\section{Acknowledgments}

None.

\section{Conflicts of interest}

Author declares there are no conflicts of interest.

\section{Funding}

None.

\section{References}

1. Bozec A, Poissonnet G, Chamorey E, et al. Results of vocal rehabilitation using tracheoesophageal voice prosthesis after total laryngectomy and their predictive factors. Eur Arch Otorhinolaryngol. 2009;267(5):751-758.

2. Lundstrom E. Voice Function and Quality of Life in Laryngectomees Departamento de Ciências Clínicas Intervenção e Tecnologia Instituto Karolinska Suécia. 2009.

3. Bocklet T, Riedhammer K, Noth E, et al. Automatic Intelligibility Assessment of Speakers after Laryngeal Cancer by Means of Acoustic Modeling. $J$ Voice. 2011;26(3):390-397.

4. Silveira A. Sistema de Gestão de Conhecimento na Avaliação da Qualidade de Vida relacionada com a Saúde em Oncologia: Proposta de Modelo para Implementação na Prática Clínica Instituto de Ciências Biomédicas Abel Salazar Universidade do Porto Porto. 2011. 
5. Ribeiro J, Santos C. Validation Study of the Portuguese version of the QLC-C30-V3. Psicologia Saúde \& Doenças. 2008;9(1):89-102.

6. Ward E, As-Brooks C. Head and Neck Cancer: Treatment Rehabilitation and Outcomes: Plural Publishing. 2006.

7. Boscolo-Rizzo P, Maronato F, Marchiori C, et al. Long-Term Quality of Life after Total Laryngectomy and Postoperative Radiotherapy Versus Concurrent Chemo radiotherapy for Laryngeal Preservation. Laryngoscope. 2008;118(2):300-306.

8. Ribeiro-Pais J, Pinto C, Santos C. Validation Study of the Portuguese Version of the QLQ-C30-V3. 2008.

9. Silveira A, Ribeiro C, Gonçalves J, et al. Qualidade de vida em doentes oncológicos da cabeça e pescoço tratados no Instituto Português de Oncologia do Porto: comparação de instrumentos de medida. Revista Portuguesa de Saúde Pública. 2009;8:59-66.

10. Mallis A, Goumas P, Mastronikolis N, et al. Factors influencing quality of life after total laryngectomy: a study of 92 patients. European Review for Medical and Pharmacological Sciences. 2011;15(8):937.

11. Fahsl S, Keszte J, Meister E, et al. Clinical Relevance of Qualityof-Life Data in Laryngectomized Patients. Laryngoscope. 2012;122(7):1532-1538.
12. Giordano L, Toma S, Teggi R, et al. Satisfaction and Quality of Life in Laryngectomees after Voice Prosthesis Rehabilitation. Folia Phoniatr Logop. 2011;63(5):231-236.

13. Op de Coul BM, Ackerstaff AH, Van as-Brooks CJ, et al. Quality of life assessment in laryngectomized individuals: do we need additions to standard questionnaires in specific clinical research projects? Clin Otolaryngol. 2005;30(2):169-175.

14. Ribeiro J. Qualidade de Vida e Doença Oncológica Faculdade de Psicologia e de Ciências da Educação Universidade do Porto Porto. 2001.

15. Sayed S, Manikantan K, Khode S, et al. Perspectives on quality of life following total laryngectomy. G Ital Med Lav Ergon. 2009;31(3 Suppl B):B21-B24.

16. Bjordal K, Hammerlid E, Ahlner-ElmqvistM, et al. Quality of Life in Head and Neck Cancer Patients: Validation of the European Organization for Research and Treatment of Cancer Quality of Life QuestionnaireH\&N35 J Clin Oncol. 1999;17(3):1008-1019. 